\title{
Bonding Quality of Copper-Nickel Fine Clad Metal Prepared by Surface Activated Bonding
}

\author{
Kyung Hoon $\mathrm{Kim}^{1}$, Soon Hyung Hong ${ }^{1}$, Seung Il $\mathrm{Cha}^{2}$, Sung Chul Lim ${ }^{3}$, \\ Hyouk Chon Kwon ${ }^{3}$ and Won Kyu Yoon ${ }^{4}$ \\ ${ }^{1}$ Department of Materials Science and Engineering, Korea Advanced Institute of Science and Technology, \\ 373-1 Guseong-dong, Yuseong-gu, Daejeon 305-701, Korea \\ ${ }^{2}$ Korea Electrotechnology Research Institute, 28-1 Seongju-dong, Changwon-si, Gyeongsangnam-do, 641-120, Korea \\ ${ }^{3}$ Korea Institute of Industrial Technology, 7-47 Songdo-dong, Yeonsu-gu, Inchon 406-840, Korea \\ ${ }^{4}$ HEESUNG METAL LTD., 693-1 Gojan-dong, Namdong-gu, Inchon 405-310, Korea
}

\begin{abstract}
The effects of surface roughness and heat treatment on the bonding quality of surface-activated bonding (SAB)-treated copper-nickel fine clad metals were investigated. An increase in the surface roughness of the copper layer decreased the peel strength after cladding, indicating that increases in the surface roughness decreased the contact area between the clad materials in the SAB cladding process, unlike conventional cold rolling that induces high deformation. In addition, the peel strength of the clad metals increased up to $7.3 \mathrm{~N} / \mathrm{mm}$ with decreasing surface roughness of the copper layer after heat treatment. The change in the total sheet resistance of the copper-nickel clad metal with the heat treatment depended on the balance between a decrease in the sheet resistance due to the reduction of dislocation and the increase in the heat treatment temperature, and an increase in the sheet resistance due to the diffusion of nickel in the copper direction. [doi:10.2320/matertrans.M2009354]
\end{abstract}

(Received October 20, 2009; Accepted January 12, 2010; Published February 24, 2010)

Keywords: bonding quality, copper-nickel clad, surface activation, low pressure bonding

\section{Introduction}

In recent years, much attention has been directed toward providing very thin (micrometer range) and precise bonding of dissimilar metals because advances in electronic devices require multifunction, high-speed, and reliable processes and materials. A number of different processes are currently used to clad various materials, including rolling, ${ }^{1)}$ extrusion ${ }^{2)}$ and explosive forming. ${ }^{3)}$ These processes accompany deformation of contacting surfaces inducing removal of surface oxides and atomic diffusion by applied high pressure and temperature. ${ }^{4-7)}$ Therefore, rough surface provides increasing contact area, localized deformation and diffusion path focused pressure and initiate deformation under applied temperature and pressure, hence increasing bonding strength. ${ }^{8)}$ However, the deformation produce high dislocation density near bonded region, and, at the same time, these processes require relatively thick clad metals, which is not suitable for microelectronics applications.

Surface Activated Bonding (SAB) has been developed by T. Suga and his colleagues ${ }^{9,10)}$ to joining of similar and dissimilar materials without any heating process at room temperature.

As shown in Fig. 1, SAB process gives new opportunity for metal cladding by cleaning contacted metal surfaces with plasma, instead of high temperature deformation under high pressure, and by cladding metals with low pressure cold rolling condition.

T. Suga and his colleagues reported that not only to metal has metal been bonded, ${ }^{11)}$ but also to different materials such as $\mathrm{Si}, \mathrm{SiO}_{2},{ }^{12)} \mathrm{SiC}, \mathrm{Si}_{3} \mathrm{~N}_{4},{ }^{13)}$ steel ${ }^{14)}$ and $\mathrm{Al}_{2} \mathrm{O}_{3},{ }^{15)}$ and the influence of surface roughness for room temperature MEMS device seal-bonding using SAB technique has been investigated. ${ }^{16)}$ However, the effect of initial surface roughness of clad materials on metallurgical status of bonded region is

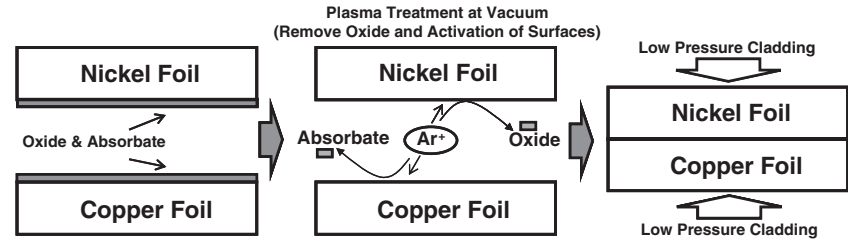

Fig. 1 Schematic of surface activation bonding.

not clearly demonstrated. And also the mechanical properties and electrical properties of clad metal utilizing SAB for electronic devices are not well established. In addition, effect of post-treatment such as heat treatment on the performance of these clad metals should be investigated further.

In this study, the effect of surface roughness and posttreatment on the peel strength and electric conductivity of $\mathrm{Cu}-\mathrm{Ni}$ clad metals are investigated. Based on the metallurgical observation after process, the relationship between surface roughness and post-treatment and their properties are examined. The surface of thin copper foil was modified by abrading it with polishing papers of different grits before the foil was clad with unmodified nickel foil using the SAB process.., 10$)$ The bonding quality of the fine clad metals with varying surface roughness values and heat treatment conditions were evaluated via peeling tests, tensile tests, metallographic examinations, and electrical resistance measurements.

\section{Experimental Procedure}

\subsection{Materials and cladding method}

Oxygen-free high thermal conductivity 50- $\mu \mathrm{m}$-thick copper and annealed $25-\mu \mathrm{m}$-thick nickel (99.90\%) foil, both $150 \mathrm{~mm}$ wide, were used in this experiment. The experimen- 
Table 1 Surface roughness before and after modification.

\begin{tabular}{cc}
\hline Clad Materials Surface & Ra \\
\hline Unmodified nickel foil & $152.0 \mathrm{~nm} \pm 24.3 \mathrm{~nm}$ \\
$\quad$ (As nickel foil) & \\
Unmodified copper foil & $148.4 \mathrm{~nm} \pm 20.1 \mathrm{~nm}$ \\
$\quad$ (As copper foil) & \\
Modified copper foil & $419.1 \mathrm{~nm} \pm 29.3 \mathrm{~nm}$ \\
by 600 grit silicon carbide paper & \\
Modified copper foil & $736.4 \mathrm{~nm} \pm 89.1 \mathrm{~nm}$ \\
by 220 grit silicon carbide paper & \\
Modified copper foil & $1044.9 \mathrm{~nm} \pm 108.6 \mathrm{~nm}$ \\
by 80 grit silicon carbide paper &
\end{tabular}

tal process consisted of preparation of the clad composition metal samples, cladding of the two layers by SAB, and heat treatment of the SAB-clad metal. Copper foils with four different degrees of surface roughness were prepared to analyze the effects of roughness on the peel strength. Commercially available rolled copper foil with no surface modification was used as the benchmark roughness level. Three other roughness levels were achieved by abrading the surface with polishing papers of different grits.

The typical rolled copper foil used in this experiment had a roughness of $148.4 \mathrm{~nm}$. Copper foil surfaces with 419.1, 736.4 and $1044.9 \mathrm{~nm} \mathrm{Ra}$ roughness values were obtained using silicon carbide papers (Stuer) with grits of 600,220 , and 80, respectively. Table 1 lists both the mean value and the standard deviation of the surface roughness. The unmodified nickel foil had a surface roughness of $152.0 \mathrm{~nm}$.

After abrading the copper foil surface, the copper and nickel foil rolls were mounted in a surface activation system for simultaneous cladding. After the evacuation of the SAB chamber, each of the copper and nickel foil samples was activated in the plasma treatment units by removal of their surface absorption and oxide layers. Once the activated surfaces were free from contamination, the copper and nickel foil samples were sent to the rolling unit with a reduction ratio of less than $1 \%$ (Thickness change: $<0.75 \mu \mathrm{m}$ at a roll load of $27.5 \mathrm{kN}$ and a roll diameter of $150 \mathrm{~mm}$ ). The copper and nickel foil specimens were then continually clad in the rolling units. Continual roll-to-roll plasma treatment of the two surface layers was accomplished by $1000 \mathrm{~W}$ (plasma power) argon plasma treatment units with a roll diameter of $150 \mathrm{~mm}$, a winding speed of $1.5 \mathrm{~m} / \mathrm{min}$ and a roll load of $27.5 \mathrm{kN}$

\subsection{Peel test}

The peel (bonding) strength of the copper-nickel clad metal was measured using the $180^{\circ}$ peel test. The test samples were cut into 5-mm-wide oblong shapes and tested at a peeling speed of $0.1 \mathrm{~mm} / \mathrm{s}$. The peeling test was performed using a micro-tensile testing machine (model 8800, Instron). The average peeling strength was calculated by the following equation: average peel strength $=$ average load/bond width $(\mathrm{N} / \mathrm{mm})$. The interface between the copper-nickel clad metal was observed with an optical microscope and by scanning electron microscopy (SEM). The surface was analyzed by energy dispersive X-ray analysis after peel tests of the heattreated samples.

\subsection{Heat treatment}

After cladding, the SAB-treated copper-nickel clad metals were encapsulated in quartz ampoules at $1.333 \times 10^{-2} \mathrm{~Pa}$ to investigate the influence of heat treatment on the bonding quality and the interface morphology. This allowed elimination of the effect of oxygen on the interfacial microstructure for the clad sample. The encapsulated clad material was annealed at $573 \mathrm{~K}$ or $873 \mathrm{~K}$ for $3.6 \mathrm{ks}$.

\subsection{Clad metal tensile testing}

The specimens were first machined and then annealed at different temperatures. A clad tensile test was conducted using the micro-tensile testing machine and ASTM-E8M to determine the mechanical properties of each specimen.

\subsection{Electrical resistance}

The electrical resistivity of the samples was measured with a resistivity test unit (RM2, Jandel) fitted with a four-point cylindrical probe. Because the clad material was composed of two kinds of sheets, the sheet resistance of the copper, which has a lower sheet resistance than nickel, was measured and compared with the values resulting from various heat treatment conditions.

\section{Results and Discussion}

\subsection{Effect of roughness on the peel strength of copper- nickel clad metal}

In the conventional cold rolling process for metal-metal cladding, the brittle surface layer of the metal resulting from a surface scratch brushing process is subjected to an increasing amount of normal pressure, eventually deforming in the rolling direction during the simultaneous rolling of the two strips. This exposes some underlying surface cracks below the metal. The new clean metal surface is then extruded under high reduction ratio conditions in addition to experiencing the scratch effect. However, in this new SAB process, the high vacuum coupled with the plasma etching process creates new clean metal surfaces for each metal more effectively than any conventional cladding process without any excessive deformation at a $40 \%-60 \%$ reduction ratio. In addition, there is almost no atmospheric invasion to react with the activated clean metal surfaces.

Figure 2 shows the effect of changes in the copper layer surface roughness on the bond strength of the copper-nickel clad metal. The peel strength increased as the surface roughness of the copper layer decreased. Indeed, increasing the surface roughness of the copper layer decreases the contact area between the clad materials in the SAB cladding process, unlike a conventional cold rolling process. As shown in Fig. 3(d), the interface of the copper-nickel clad metal with low peel strength $(0.93 \mathrm{~N} / \mathrm{mm})$, formed from a modified copper layer $(\mathrm{Ra}=1044.9 \mathrm{~nm})$ and unmodified nickel layer $(\mathrm{Ra}=152.0 \mathrm{~nm})$, had an interface morphology that appears little different than the initial surface morphology. Rough surface and high reduction ratio for cladding are not necessary in the SAB process. However, the SAB process depends on the contact area, as in the conventional cold rolling case, because the basic bonding mechanism of the new clean metal surface for metal generation and adhesion is 


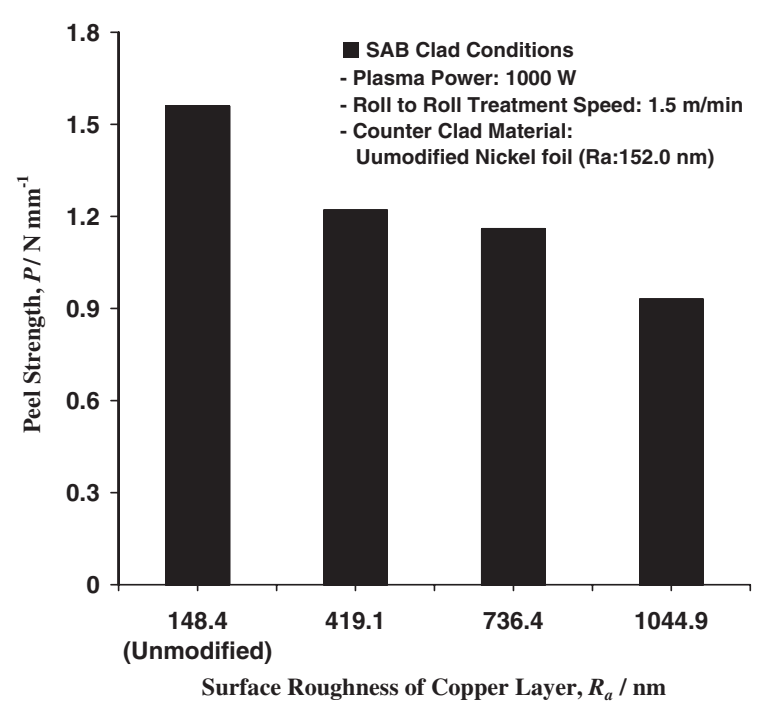

Fig. 2 Effect of surface roughness on peel strength for four different copper layer surfaces roughness values.

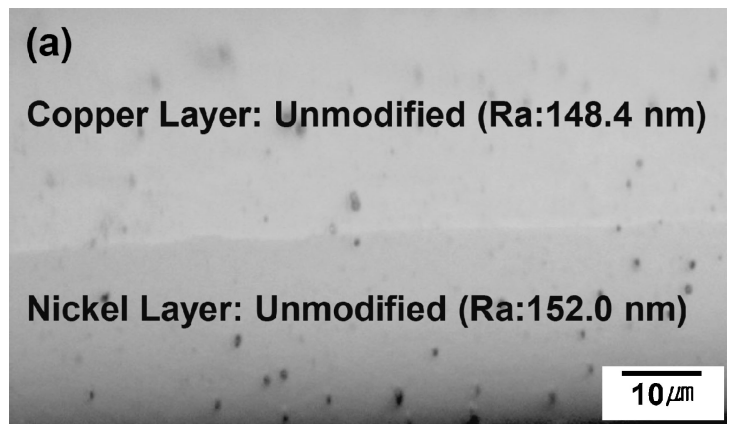

(c)

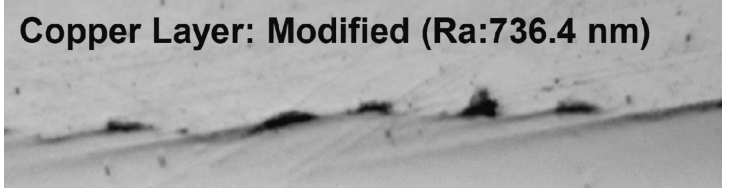

Nickel Layer: Unmodified (Ra:152.0 nm) $\overline{10 \mu \mathrm{m}}$

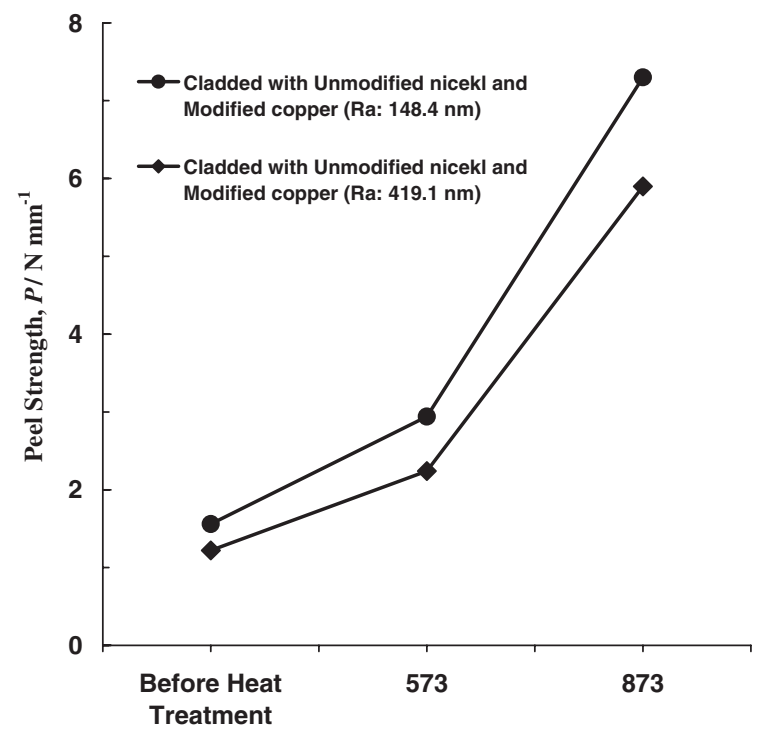

Heat Treatment Temperature, $T / \mathrm{K}$

Fig. 4 Effect of heat treatment before and after heat treatment for $3.6 \mathrm{ks}$ on the peel strength for various surface roughness values of copper.

\section{(b)}

\section{Copper Layer: Modified (Ra:419.1 nm)}

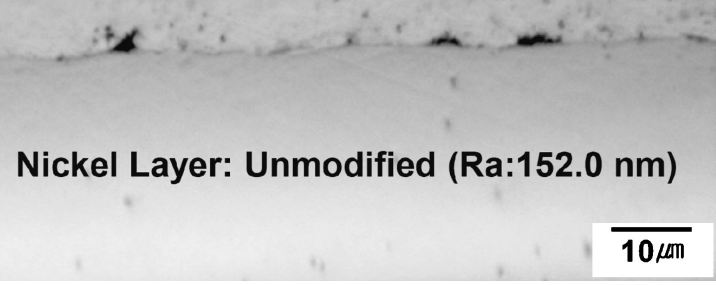

(d)

Copper Layer: Modified (Ra:1044.9 nm)
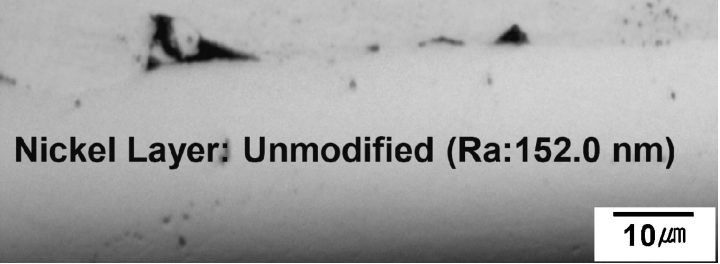

Fig. 3 Optical microscope images of the copper-nickel interface showing the effect of various surface roughness values of copper with unmodified nickel $(\mathrm{Ra}=152.0 \mathrm{~nm})$ for $(\mathrm{a})$ unmodified copper $(\mathrm{Ra}=148.4 \mathrm{~nm})$, (b) modified copper $(\mathrm{Ra}=419.1 \mathrm{~nm})$, (c) modified copper $(\mathrm{Ra}=736.4 \mathrm{~nm})$, and $(\mathrm{d})$ modified copper $(\mathrm{Ra}=1044.9 \mathrm{~nm})$.

identical. As shown in Fig. 3(a), a copper-nickel clad metal interface with high peel strength $(1.56 \mathrm{~N} / \mathrm{mm})$, formed from an unmodified copper layer $(\mathrm{Ra}=148.4 \mathrm{~nm})$ and a nickel layer $(\mathrm{Ra}=152.0 \mathrm{~nm})$, appeared flat without a detached area because the initial surface roughness was relatively low. Therefore, copper-nickel clad metal with high peel strength requires a flat surface (i.e., low roughness of the cladding component materials) during the SAB process. The SAB cladding process has good characteristics that include flat interface morphology and relatively unchanged mechanical properties with a fine clad metal form.

\subsection{Effect of heat treatment on the bonding strength after the SAB process}

Figure 4 shows the effect of the heat treatment on the peel strength of copper-nickel SAB-clad metal. Two coppernickel clad metal specimens with different peel strengths, $1.22 \mathrm{~N} / \mathrm{mm}$ (clad using a surface-modified copper layer with $\mathrm{Ra}=419.1 \mathrm{~nm}$ and nickel layer with $\mathrm{Ra}=152.0 \mathrm{~nm})$ and $1.56 \mathrm{~N} / \mathrm{mm}$ (clad using an unmodified copper layer with $\mathrm{Ra}=148.4 \mathrm{~nm}$ and a nickel layer with $\mathrm{Ra}=152.0 \mathrm{~nm}$ ) were selected to determine the effect on the peel strength of annealing at $573 \mathrm{~K}$ or $873 \mathrm{~K}$ for $3.6 \mathrm{ks}$. The peel strength of 
(a) Before Heat treatment

Copper Layer: Modified (Ra:419.1 nm)

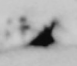

Nickel Layer: Unmodified (Ra:152.0 nm)
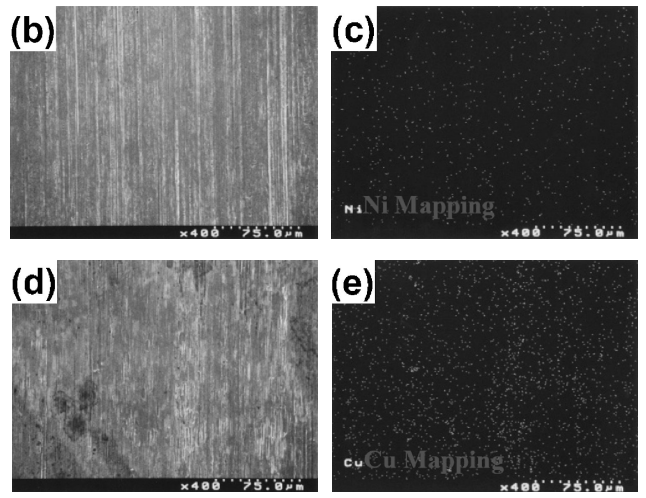

(e)

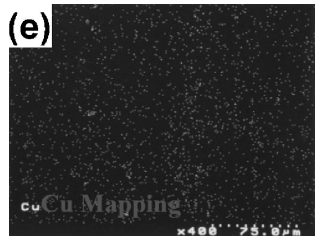

Fig. 5 Optical microscope image of copper-nickel clad metal before heat treatment, with SEM and EDS analyses after a peel test: (a) interface structure of modified copper $(\mathrm{Ra}=419.1 \mathrm{~nm})$ and unmodified nickel (Ra: $152.0 \mathrm{~nm})$; (b), (c) SEM image and EDS mapping of the peeled copper layer; (d), (e) SEM image and EDS mapping of the peeled nickel layer.
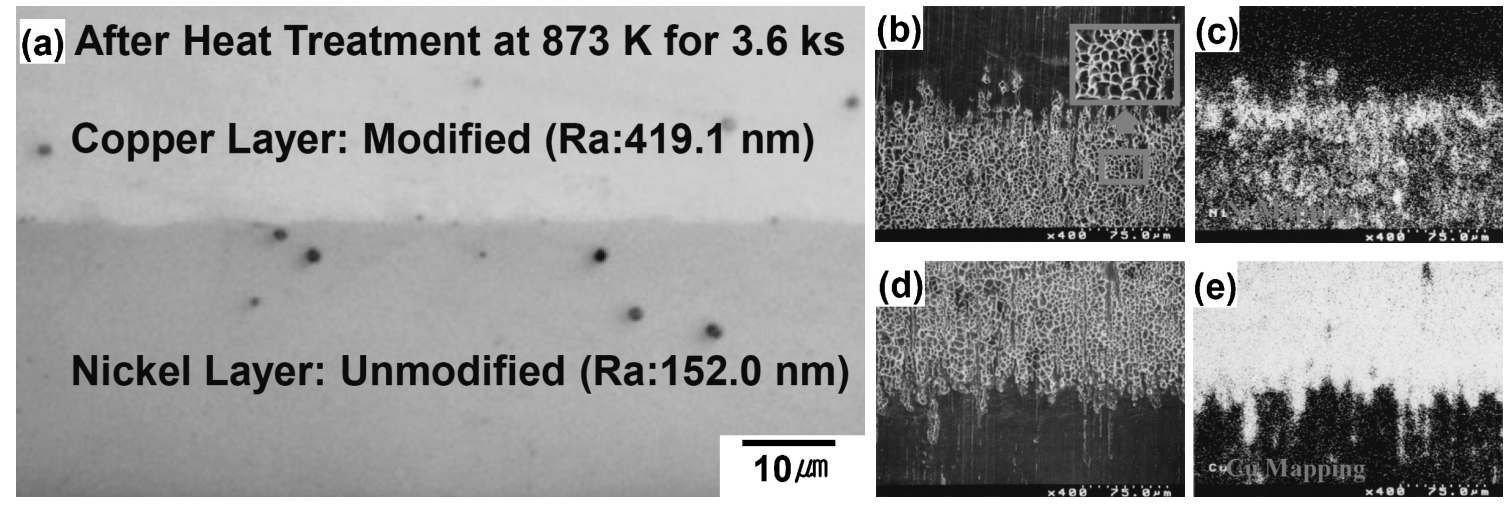

Fig. 6 Optical microscope image of copper-nickel clad metal after heat treatment at $873 \mathrm{~K}$ for $3.6 \mathrm{ks}$, with SEM and EDS analyses after a peel test: (a) interface structure of modified copper $(\mathrm{Ra}=419.1 \mathrm{~nm})$ and unmodified nickel $(\mathrm{Ra}=152.0 \mathrm{~nm})$; (b), (c) SEM image and EDS mapping of the peeled copper layer; (d), (e) SEM image and EDS mapping of the peeled nickel layer.

the unmodified copper $(\mathrm{Ra}=148.4 \mathrm{~nm})$ and nickel $(\mathrm{Ra}=$ $152.0 \mathrm{~nm}$ ) clad sample increased up to the ultimate tensile strength (UTS) of the nickel foil $(250 \mathrm{MPa})$ to reach 7.3 $\mathrm{N} / \mathrm{mm}$ because of the annealing treatment. Moreover, in the surface-modified copper $(\mathrm{Ra}=419.1 \mathrm{~nm})$ and unmodified nickel $(\mathrm{Ra}=152.0 \mathrm{~nm})$ clad sample, the peel strength increased by approximately three times, from 1.22 to $5.9 \mathrm{~N} / \mathrm{mm}$.

The reason for the difference in the peel strength between the two heat-treated clad metals was that the effect of diffusion on the peel strength is proportional to the contact area, heat treatment temperature, and time. Thus, for a fixed heat treatment time $(3.6 \mathrm{ks})$ and temperature $(873 \mathrm{~K})$, the peel strength depended on the contact quality of the clad components, including the contact area factor due to the difference of surface roughness of each clad materials.

As a result, the unmodified copper $(\mathrm{Ra}=148.4 \mathrm{~nm})$ and nickel $(\mathrm{Ra}=152.0 \mathrm{~nm})$ clad sample, which had a larger contact area than the modified copper $(\mathrm{Ra}=419.1 \mathrm{~nm})$ and unmodified nickel $(\mathrm{Ra}=152.0 \mathrm{~nm})$ clad sample before the heat treatment, showed a higher peel strength $(7.3 \mathrm{~N} / \mathrm{mm})$ after heat treatment.

Figure 5(a) shows that the interface of the surfacemodified copper $(\mathrm{Ra}=419.1 \mathrm{~nm})$ and unmodified nickel $(\mathrm{Ra}=152.0 \mathrm{~nm})$ clad metal is very rough; in fact, a gap between the copper and nickel interface can be observed.
Unlike the conventional cold rolling process, the SAB process in general applies very low pressure so that deformation by reduction $(<1 \%$ reduction ratio at a roll load of $27.5 \mathrm{kN}$ and a roll diameter of $150 \mathrm{~mm}$ ) does not sufficiently overcome the initial surface roughness of materials include not only $R_{a}$ but also $R_{\max }$. Also in the $\mathrm{SAB}$ process, the bonding factor does not depend entirely on the creation of new clean metal surfaces by deformation (high reduction ratio by roll pressing). The $\mathrm{SAB}$ process creates a clean activated metal surface by plasma activation, which removes the surface oxide. It also creates an activation area under high-vacuum conditions, which prevents recontamination.

Figure 6(a) shows optical microscope photographs of the interface between the surface-modified copper layer $(\mathrm{Ra}=$ $419.1 \mathrm{~nm})$ and the unmodified nickel layer $(\mathrm{Ra}=152.0 \mathrm{~nm})$ after heat treatment at $873 \mathrm{~K}$ for $3.6 \mathrm{ks}$. It is clear that the heat treatment eliminates the gap in the interface between the two layers by diffusion of atoms from each material. In addition, the bonding quality of the modified copper $(\mathrm{Ra}=419.1 \mathrm{~nm})$ and unmodified nickel $(\mathrm{Ra}=152.0 \mathrm{~nm})$ clad metal improved up to the tearing strength of the nickel foil during the peeling test.

The appearance of the peeled surfaces after the peeling test was compared using SEM before and after the heat treatment at $873 \mathrm{~K}$ for $3.6 \mathrm{ks}$. Figures 5(b) and 5(d) indicate 

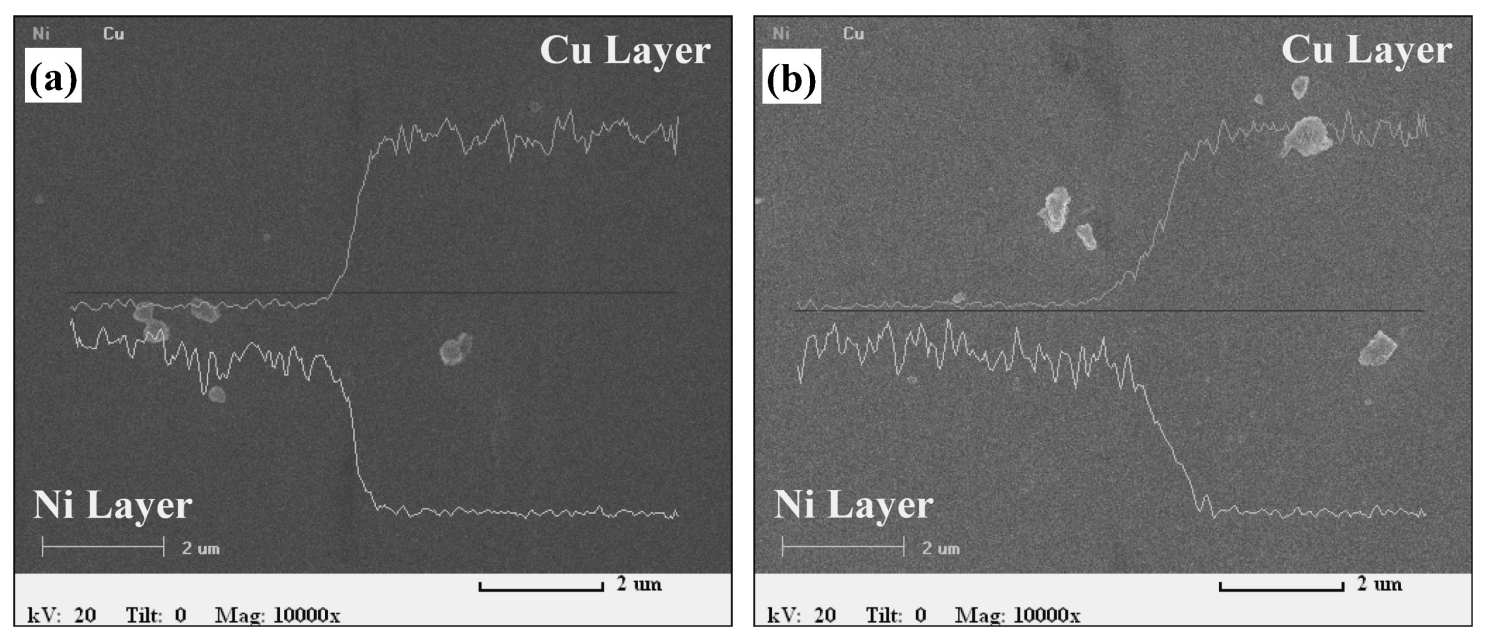

Fig. 7 Concentration distance profiles of copper $(\mathrm{Ra}=419.1 \mathrm{~nm})$ and unmodified nickel $(\mathrm{Ra}=152.0 \mathrm{~nm})(\mathrm{a})$ before and $(\mathrm{b})$ after heat treatment at $873 \mathrm{~K}$ for $3.6 \mathrm{ks}$.

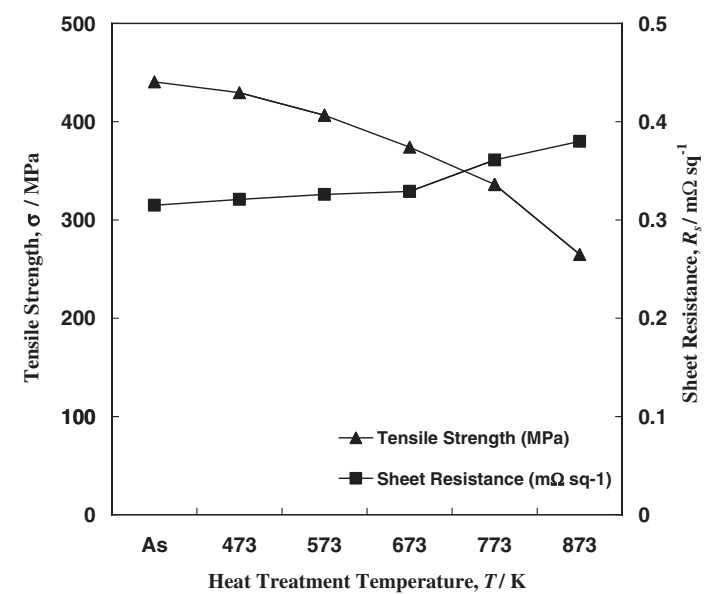

Fig. 8 Effect of heat treatment on the tensile strength and sheet resistance of the copper layer.

less bonding strength than in Figs. 6(b) and 6(d), which show a surface consisting of many microvoids and dimples created by interdiffusion. In addition, Fig. 7 shows the EDS concentration-distance profiles at the interface between the surfacemodified copper layer $(\mathrm{Ra}=419.1 \mathrm{~nm})$ and the unmodified nickel layer $(\mathrm{Ra}=152.0 \mathrm{~nm})$ before and after heat treatment at $873 \mathrm{~K}$. Both the copper and nickel have notably interdiffused in the heat-treated clad sample, causing the increase in peel strength. The SAB treatment is thus a key factor in the initial surface roughness of clad component materials, implying that a flat surface (i.e., low surface roughness) of clad component materials leads to high peel strength.

\subsection{Effect of heat treatment on the electrical and mechanical properties after SAB}

The UTS values and the copper layer sheet resistance of different specimens were determined using the stress-strain curves and the resistance value of copper-nickel clad metal annealed for $3.6 \mathrm{ks}$ and at different temperatures. Figure 8 shows that the UTS value of the copper-nickel clad metals decreased as the heat treatment temperature increased due to grain growth and re-crystallization. Otherwise, in the early stages, the change in the total sheet resistance of the copper layer was small due to the balance of the sheet resistance decreasing caused by the reduction in the number of dislocations as the heat treatment temperature increased, and the sheet resistance increasing caused by the diffusion of nickel in the copper direction. However, above $673 \mathrm{~K}$, the total sheet resistance of the copper layer increased sharply, which implies that the diffusion of nickel was dominant. Moreover, this phenomenon corresponded to an abrupt increase of the bond strength when the copper-nickel clad metal was heat treated at temperatures above $573 \mathrm{~K}$. Therefore, where conductivity is important in clad material applications, selecting an appropriate heat treatment condition is essential as this can have a detrimental effect on the conductivity.

\section{Conclusions}

(1) An increase in the surface roughness of the copper layer decreased the peel strength between the copper and nickel in clad materials. This phenomenon was observed in 148.4, 419.1, 736.4 and $1044.9 \mathrm{~nm}$ Ra copper surface layer roughness samples. This indicates that increases in the surface roughness decrease the contact area between the clad materials in the SAB cladding process. This is unlike conventional cold rolling, which induces high deformation.

(2) Unmodified copper $(\mathrm{Ra}=148.4 \mathrm{~nm})$ and nickel $(\mathrm{Ra}=$ $152.0 \mathrm{~nm})$ clad metal had a higher peel strength $(7.3 \mathrm{~N} / \mathrm{mm})$ than that of modified copper $(\mathrm{Ra}=419.1 \mathrm{~nm})$ and unmodified nickel $(\mathrm{Ra}=152.0 \mathrm{~nm})$, which had a peel strength of $5.9 \mathrm{~N} / \mathrm{mm}$ after heat treatment. The former had a larger contact area than the latter before heat treatment, explaining why the peel strength of a clad sample with an initial low surface roughness was higher than a clad sample with an initial high surface roughness. This is a characteristic of the SAB process, which is unlike conventional cold rolling.

(3) Heat treatment reduced the gap in the interface between the two clad layers by diffusion of the atoms of each material. Moreover, the peel strength of the modified copper $(\mathrm{Ra}=419.1 \mathrm{~nm})$ and unmodified nickel $(\mathrm{Ra}=$ $152.0 \mathrm{~nm}$ ) clad metal improved up to the tearing strength of the nickel foil during the peeling test. 
(4) In the early stages of heat treatment, the change in the total sheet resistance of the copper layer was small due to the balance between the decrease in the sheet resistance caused by the reduction of the dislocations with an increase in the heat treatment temperature, and the increase in the sheet resistance caused by diffusion of nickel in the copper direction. However, above $673 \mathrm{~K}$, the total sheet resistance of the copper layer increased sharply, indicating that the diffusion of nickel was dominant.

\section{REFERENCES}

1) M. S. A. Nezhad and A. H. Ardakani: J. Mater. Design 30 (2009) 1003 1009.

2) J. M. Story, B. Avitzur and W. C. Hahn, Jr.: J. Eng. Ind. Trans. ASME Series B 98 (1976) 909-913.

3) S. J. Kim, S. H. Paik and M. Y. Huh: J. Korean Inst. Met. Mater. 32 (1994) 1558.

4) H. Yan and J. G. Lenard: Mater. Sci. Eng. A 385 (2004) 419-428.

5) J. A. Schey: Tribology in Mrtal working, (ASM, Metals Park, Ohio,
1983).

6) H. Y. Wu, S. Lee and J. Y. Wang: J. Mat. Proc. Technol. 75 (1988) 173-179.

7) N. D. Lucaschkin, A. P. Borissow and A. I. Elrikh: J. Mater. Proc. Technol. 66 (1997) 264-269.

8) C. Clemenson, O. Juelstorp and N. Bay: Met. Constr. 18 (1986) 625629.

9) T. Suga, K. Miyazawa and Y. Yamagata: MRS Int. Meeting on Advanced Materials, 8, ed. by N. Iwamoto and T. Suga, (1989) p. 257.

10) T. Suga and K. Miyazawa: Acta/Scripta Metallurgica Proc. Series, Vol. 30, ed. by M. Rühle, A. G. Evans, M. F. Ashy and J. P. Hirth, (1990) p. 189.

11) T. Akatsu, N. Hosoda, T. Suga and M. Rühle: J. Mater. Sci. 34 (1999) 4133-4139.

12) N. Hosoda, Y. Kyogoku and T. Suga: J. Mater. Sci. 33 (1998) 253-258.

13) T. Suga, Y. Takahashi, H. Takagi, Y. Ishida, G. Gibbesch and G. Elssner: Acta Metall. Mater. 40 (1992) S133-S137.

14) L. Yang, N. Hosoda and T. Suga: Interface Sci. 5 (1997) 279-286.

15) T. Akatsu, G. Sasaki, N. Hosoda and T. Suga: J. Mater. Res. 12 (1997) 852-856.

16) H. Okada, T. Itoh and T. Suga: Sensors and Actuators A 144 (2008) 124-129. 